\title{
Dysphagia - A Presenting Symptom of Forestier Disease
}

\section{CER Gibbons}

FRCS

Senior House Officer

Maj F Khan
FRCS RAMC
Senior Registrar

Royal National Orthopaedic Hospital, Brockley Hill, Stanmore, Middx

SUMMARY: We describe the case of a 48-year-old lady who developed dysphagia to solids. Barium swallow and lateral spine radiographs confirmed Forestier disease.

\section{Case Report}

A 48-year old lady presented to the Surgical Out Patient Department with a three month history of dysphagia to solids. Her appetite was normal and she denied weight loss. There was no history of neck stiffness or pain.

Clinical examination and routine blood tests were unremarkable. Indirect laryngoscopy was normal. A barium swallow was arranged which showed indentation of the cervical oesophagus (Fig 1). The remaining oesophagus appeared normal. Lateral cervical spine radiographs confirmed a bridging mass of exuberant bone formation anteriorly, between the fifth and sixth cervical vertebrae, with preservation of the disc spaces.

Radiographic features were consistent with Forestier disease (ankylosing hyperostosis, or diffuse ideopathic hyperostosis). The lady remained symptomatic but declined any further investigation or treatment.

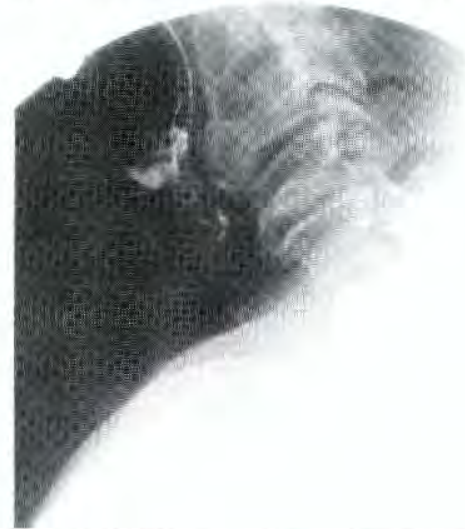

Fig 1. Barium swallow showing indentation of the upper oesophagus by a bridging mass of new bone formation from the anterior vertebral bodies of the cervical spine.

\section{Discussion}

Forestier Disease (ankylosing hyperostosis or diffuse ideopathic skeletal hyperostosis) is a non-inflammatory degenerative disease resulting in the formation of small osteophytes along the anterior and lateral aspect of the spinal column. These tend to coalesce and result in lifू্̧, ossification along the spine (1).

The condition was first described by Jacques Fore in 1950 after testing spinal mobility in cadavers. A?ter anatomical and radiographic studies it was shown thd a number of cases of ankylosis were associated with á flowing pattern of new bone formation along the actejior aspect of the spinal column. These findings werब found in a number of young adults. Extraspinatbone production at ligamentous and tendonous attachmentitivas also demonstrated.

Forestier disease most frequently presents in me the age of fifty. The clinical manifestations are strioi mild irrespective of the site of hyperostosis. Spinal saim if present, is usually mild, and may be associated $8 \mathrm{i} \mathscr{G}$ a decrease in mobility. At the cervical level a lar and prominent spur may cause dysphagia (2), howe. it remains an uncommon cause of this symptom (3).

The diagnosis of Forestier disease is a radiological Usually the bony outgrowths affect several comı्लि0 vertebrae. The lower thoracic spine is most freque affected. Anterior and lateral spurs occur in the e $\overrightarrow{\Phi_{\text {gl }}}$ ly

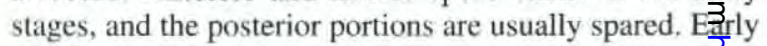
small osteophytes coalesce to form a continuous pat The disc spaces are usually well preserved. Nor segments may intervene between the continuous area롤. ossification.

Extraspinal involvement occurs in most patients long standing disease, and the pelvis is almost alugys affected. Bony outgrowths may also occur near the and shoulder joints.

This case demonstrates the presentation of Foreșier disease with dysphagia but without musculoskel@̂tal symptoms. Dysphagia is a recognised sympton cervical spine involvement but Forestier disease remฐns an uncommon cause of dysphagia. Lateral cervical radiographs are helpful in the diagnosis of dysphagie in patients with Forestier disease. However, it remifns imperative that other more serious causes of dysphägia are excluded by means of indirect laryngoscopy 잉 barium swallow or endoscopy. 
Surgical excision of the new bone formation anteriorly may be carried out in the presence of persistent and severe symptoms of dysphagia. No further treatment was carried out in this case.

\section{Acknowledgement}

We are grateful to Mr J Strachan, FRCS, Consultant Orthopaedic Surgeon, for allowing us to publish this case.

\section{REFERENCES}

1. Reswick D, Shapiro RF, Weisner KB, Niwayama G,
UTSINGER PD, SHAUL SR. Diffuse idiopathic skeletal hyperostosis. Semin Arthritis Rheum, 1978; 7: 153-87.

2. Hughes TA, Wiles CM, Lawrie BW, SMith AP. Dysphagia and sleep apnoea associated with cervical osteophytes due to diffuse idiopathic skeletal hyperostosis. J Neurol Neurosurg Psychiatry, 1994; 57: 384 .

3. Kmucha ST, Cravens RB. DISH syndrome and its role in dysphagia Otolaryngol Head Neck Surg, 1994; 100: 431-6.

\section{OBITUARIES}

Regimental Headquarters would welcome selfwritten obituaries and when completed they should be forwarded to Regimental Secretary RHQ, RAMC, Keogh Barracks, Ash Vale, Aldershot, Hants GU12 5RQ. 